\title{
Is there a role for endocannabinoids in sperm-oviduct interaction?
}

\author{
R Talevi, V Barbato, S De lorio, V Mollo, T Capriglione ${ }^{1}$, L Ricchiari, A Samo and R Gualtieri \\ Dipartimento di Biologia Strutturale e Funzionale, Università di Napoli 'Federico II', Complesso Universitario di \\ Monte Sant'Angelo, Via Cinthia, 80126 Napoli, Italy and ${ }^{1}$ Dipartimento di Scienze Biologiche, Sezione di Biologia \\ Evolutiva e Comparata, Università di Napoli 'Federico II', Via Mezzocannone 8, 80128 Napoli, Italy
}

Correspondence should be addressed to R Talevi; Email: riccardo.talevi@unina.it

\begin{abstract}
The endocannabinoid system (ECS) has been found in reproductive cells and tissues in several mammals. Spermatozoa are able to respond to anandamide, and the oviduct is able to synthesize and modulate the concentration of this endocannabinoid along the isthmic and ampullary regions. The main aim of this study was to understand whether the ECS has a role during sperm storage and release within the oviduct in cattle. Data showed that 1 ) the endocannabinoid receptors 1 and 2 (CB1 and CB2) are present in bovine spermatozoa both in the initial ejaculate and in spermatozoa bound to the oviduct in vitro; 2) CB1 receptor is still detectable in spermatozoa released from the oviduct through penicillamine but not in those released through heparin; 3) arachidonylethanolamide (AEA) does not affect sperm viability, whereas it depresses sperm progressive motility and kinetic values; 4) sperm-oviduct binding and release in vitro are not influenced by AEA; 5) AEA depresses sperm-zona pellucida (ZP) binding; 6) binding of heparin-capacitated spermatozoa to the ZP is not affected by AEA; 7) $\mathrm{N}$-acylphosphatidylethanolamine-selective phospholipase $\mathrm{D}$, the main enzyme involved in anandamide synthesis, is expressed in oviductal epithelial cells. In conclusion, secretion of AEA from epithelial cells might contribute to the oviduct sperm-reservoir function, prolonging the sperm fertile life through the depression of motility and capacitation. Capacitation signals, such as heparin, that promote sperm release, might remodel the sperm surface and cause a loss of the sperm sensitivity to AEA. Reproduction (2010) 140 247-257
\end{abstract}

\section{Introduction}

Research on the chemical and pharmacological mechanisms responsible for psychoactive properties of tetrahydrocannabinol in marijuana led to the discovery that several animals can synthesize a group of related unsaturated fatty acid derivatives named endocannabinoids, which act as endogenous ligands for the cannabinoid receptors. Arachidonylethanolamide (anandamide, AEA), the first endogenous agonist for cannabinoid receptors, and 2-arachidonoyl glycerol are the main endocannabinoids within biological fluids (Devane et al. 1992, Felder \& Glass 1998). In several tissues, AEA is released 'on demand' from membrane phospholipid precursors by $\mathrm{N}$-acylphosphatidylethanolamine-selective phospholipase D (NAPEPLD) in response to cell depolarization or mobilization of intracellular $\mathrm{Ca}^{2+}$ stores. Released AEA is quickly degraded by membrane-bound fatty acid amide hydrolase (FAAH; Habayeb et al. 2002).

AEA regulates several functions in different tissues, via interaction with two specific $G$ protein-coupled receptors, cannabinoid receptor 1 (CB1), and cannabinoid receptor 2 (CB2), whose tissue distribution and function have been described in different animal models (McPartland et al. 2007). It is known that CB1, CB2, NAPEPLD, and FAAH are widely distributed in non-neuronal somatic cells of peripheral organs, and have been found in mammalian reproductive organs, as well as in germ cells of vertebrates and invertebrates (Habayeb et al. 2002). A possible role of AEA in reproduction is suggested by its high level in reproductive secretions (Schuel et al. 2002a, 2002 b). In the male, CB1 is expressed in germ cells of both invertebrates and mammals, from spermatogonia to mature spermatozoa (Cobellis et al. 2006). A finely tuned microenvironment operated by AEA levels negatively influences the spermatogenetic process, reducing germ cell proliferation and reproductive organ weight (Cacciola et al. 2008, Lewis \& Maccarrone 2009). Apoptosis of Sertoli cells, which nurse germinal cells during their maturation inside the seminiferous tubule, is mediated through a CB2-dependent mechanism (Maccarrone et al. 2003). Recently, AEA has been shown to depress motility and capacitation of human spermatozoa (Rossato et al. 2005). Moreover, boar spermatozoa are endowed with the 
biochemical machinery to synthesize, bind, and degrade AEA (Maccarrone et al. 2005). Endocannabinoid signaling via CB1 seems to be involved during mouse embryo cleavage and transport in the oviduct (Wang et al. 2004). A role of embryonic FAAH in reducing AEA levels at potential implantation sites in the mouse is suggested by the expression of NAPEPLD from fertilization through the blastocyst stage and upregulation of FAAH in the morula and in blastocyst trophoectoderm (Wang et al. 2004, 2006, Schuel \& Burkman 2005).

Inside the oviduct, the concentration of AEA is higher in the isthmus than in the ampulla. This is due to a critical balance between AEA synthesis and its degradation along the oviduct that creates locally an appropriate 'anandamide tone' that has been correlated with normal embryo development, oviductal transport, implantation, and pregnancy (Wang et al. 2006). However, until now, the presence of an AEA gradient inside the oviduct has not been correlated with the role played by the oviductal epithelium in sperm transport and selection. Spermatozoa become fully competent for fertilization only after a series of physiological changes referred to as 'capacitation' that occurs during their journey in the female reproductive tract (Yanagimachi 1994). Since only a few spermatozoa are able to reach the oviduct ampullary region, i.e. the physiological site for fertilization, it is obvious that capacitation in vivo is accompanied by a marked sperm selection to ensure a successful fertilization and embryo development. The occurrence of the endocannabinoid system (ECS) within the female reproductive tract and its suggested role in the depression of capacitation may change the classical view about sperm capacitation. Indeed, sperm capacitation has long been considered as a continuous process that once triggered leads to hyperactivated motility, acquisition of zona pellucida (ZP) binding, and fertilization competence (Yanagimachi 1994). Recent data suggest that different mechanisms promoting or suppressing capacitation may coexist, and act at different times and in different regions during the reproductive cycle (reviewed in Hunter \& Rodriguez-Martinez (2004)). In mammals, during their journey within the oviduct, spermatozoa transiently adhere to epithelial cells of the isthmic tract creating a reservoir that assures the availability of competent spermatozoa at the time of ovulation (Wilmut \& Hunter 1984, Hunter 1988, Smith \& Yanagimachi 1990). Adhesion prolongs the sperm fertile life until poorly defined periovulatory signals induce sperm release. Several studies showed that sperm adhesion to the oviductal epithelium prevents capacitation and depresses the motility (reviewed in Hunter (2008)). However, at the time of release, adhering spermatozoa undergo rapid metabolic changes such as increase in intracellular $\mathrm{Ca}^{2+}$, protein tyrosine phosphorylation, and flagellar beat frequency, which allow their migration toward the ampullary region (Gualtieri et al. 2005). The sperm ascension through the oviduct may involve intermittent phases of adhesions and releases (Smith \& Yanagimachi 1990, Demott \& Suarez 1992, Nakanishi et al. 2004).

In the present paper, we report the presence of endocannabinoid receptors CB1 and CB2 on the surface of bovine spermatozoa, their localization on spermatozoa adhering to, and released from the oviductal epithelium in vitro, the effects of AEA on sperm viability, progressive motility, kinetics, ZP binding, and the expression of NAPEPLD in bovine oviductal epithelial cells. Overall, data support the hypothesis that endocannabinoids via CB1 play a key role in the oviductal microenvironment modulating the physiology of spermatozoa during their journey inside the female reproductive tract.

\section{Results \\ Immunolocalization of $C B 1$ and $C B 2$ in bovine spermatozoa}

Experiments were designed to localize CB1 and CB2 in bovine spermatozoa by immunofluorescence. Immunolocalization of cannabinoid receptors was carried out in the initial sperm suspension, spermatozoa bound to oviductal monolayers, and spermatozoa released from the oviduct through heparin or penicillamine $(n=4)$. In the initial sperm suspension, CB1 was localized as a bright spot at the level of the sperm neck (Fig. 1a). Differently from CB1, CB2 was localized in the rostral region of the head, in the middle piece, and slightly on the tail (Fig. 1b). In control samples pretreated with corresponding specific blocking peptides, the fluorescent signal was undetectable (Fig. $1 \mathrm{c}$ and d). In spermatozoa bound to oviductal monolayers, CB1 was localized on the sperm neck (Fig. 2a), as in the initial population, whereas CB2 was preferentially localized in a dotted pattern restricted to the rostral region of the sperm head (Fig. 2b) and more lightly on sperm middle pieces. The different distributions of CB2 in the rostral domain of spermatozoa bound to the oviductal epithelium could be due to a redistribution of the receptor in response to sperm-oviduct adhesion. Oviductal cells were not labeled in both cases (Fig. 2). Bovine spermatozoa can be released in vitro from oviductal monolayers by heparin and penicillamine, which have been previously validated as powerful inducers of sperm release (Talevi \& Gualtieri 2001, Talevi et al. 2007). Spermatozoa released by penicillamine had the same CB1 immunolocalization observed in the initial sperm population (compare Figs $1 \mathrm{a}$ and 3a). Interestingly, spermatozoa released by heparin were unlabeled (Fig. 3b). In spermatozoa released by penicillamine (Fig. 3c) or heparin (Fig. 3d), CB2 was localized as in the initial population. 

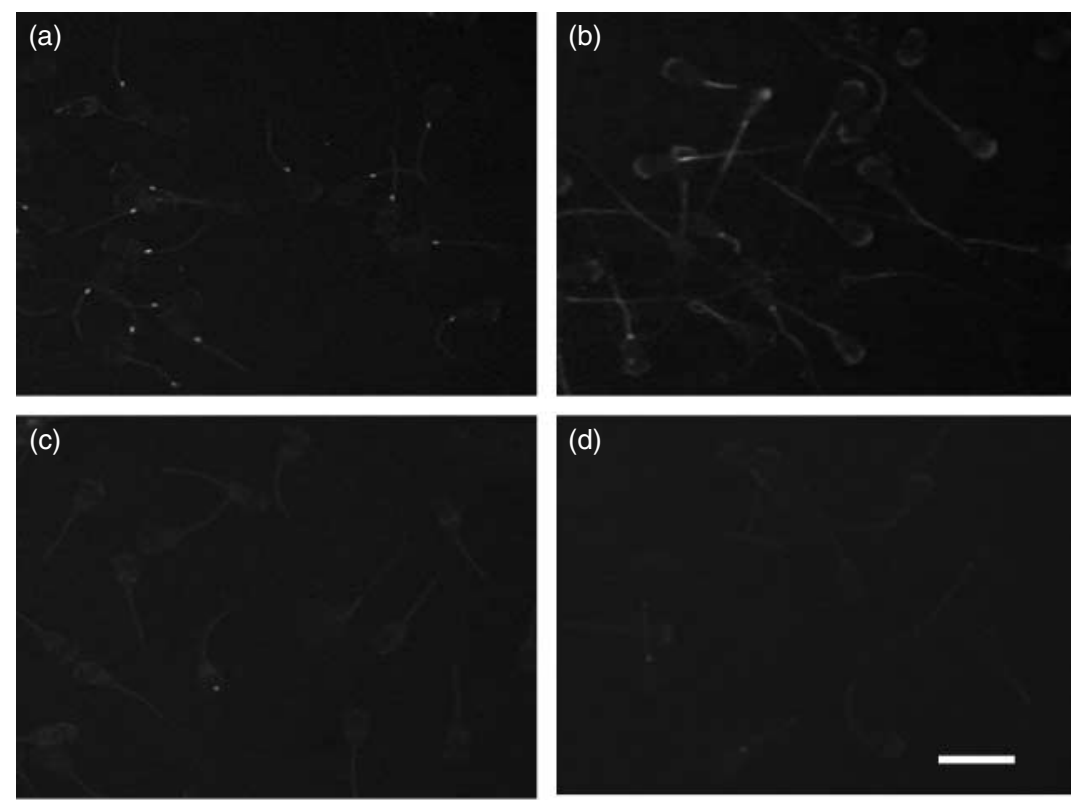

(e) 1 2 $72 \mathrm{kDa}$

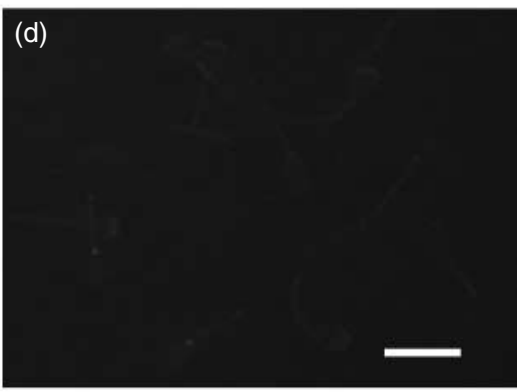

(f)

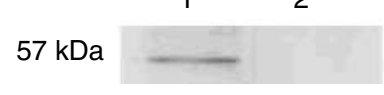

Figure 1 Immunolocalization and western blots of CB1 and CB2 in bovine spermatozoa. Localization of CB1 (a) and CB2 (b) on initial sperm suspension. Corresponding specific blocking peptides (c and d). Bar, $10 \mu \mathrm{m}$. Anti-CB1 recognized a single band of $\sim 72$ kDa M.W. (e, lane 1) while the anti-CB2 recognized a single band of $\sim 57 \mathrm{kDa}(\mathrm{f}$, lane 1 ). Controls with the corresponding specific blocking peptides (e, f, lane 2 ).

\section{Western blot analysis}

In the extracts of the initial population, anti-CB1 recognized a single band of $\sim 72 \mathrm{kDa}$ M.W. (Fig. 1e, lane 1), while the anti-CB2 recognized a single band of $\sim 57 \mathrm{kDa}$ (Fig. 1f, lane $1 ; n=4$ ). Controls with the corresponding specific blocking peptides were negative (Fig. 1e, f, lane 2), demonstrating the specificity of the immunoreactivity in both samples. Western blot analysis of spermatozoa released with the disulfide-reductant penicillamine or the sulfated glycosaminoglycan heparin $(n=4)$ showed that in penicillamine-released spermatozoa, the CB1 antibody recognized a single band of $\sim 72 \mathrm{kDa}$ (Fig. 3e, lane 3), whereas in heparinreleased spermatozoa the CB1 signal is less represented (Fig. 3e, lane 1), confirming previously results obtained with immunolocalization analysis. Parallel silver-stained gel demonstrated that the same amount of proteins was present (Fig. 3f). Controls with the corresponding specific blocking peptides were negative (Fig. 3e, lanes 2 and 4).

\section{Effect of AEA on sperm viability and progressive motility}

To understand whether AEA affects sperm viability and progressive motility, spermatozoa were treated with 2, 5, and $10 \mu \mathrm{M} \mathrm{AEA}(n=4)$. Sperm viability was not affected, whereas 5 and $10 \mu \mathrm{M}$ AEA caused a rapid and persistent decrease in sperm progressive motility (Fig. 4). Sperm motility decreased from 60 to $28 \%$ after 5 min of AEA exposure at $5 \mu \mathrm{M}$ (Fig. $4 \mathrm{a}$ ), whereas at $10 \mu \mathrm{M}$ the motility decreased from 55 to $15 \%$ (Fig. 4b). These data show that after AEA treatment, all spermatozoa are viable but most of them lose the capacity to move progressively.
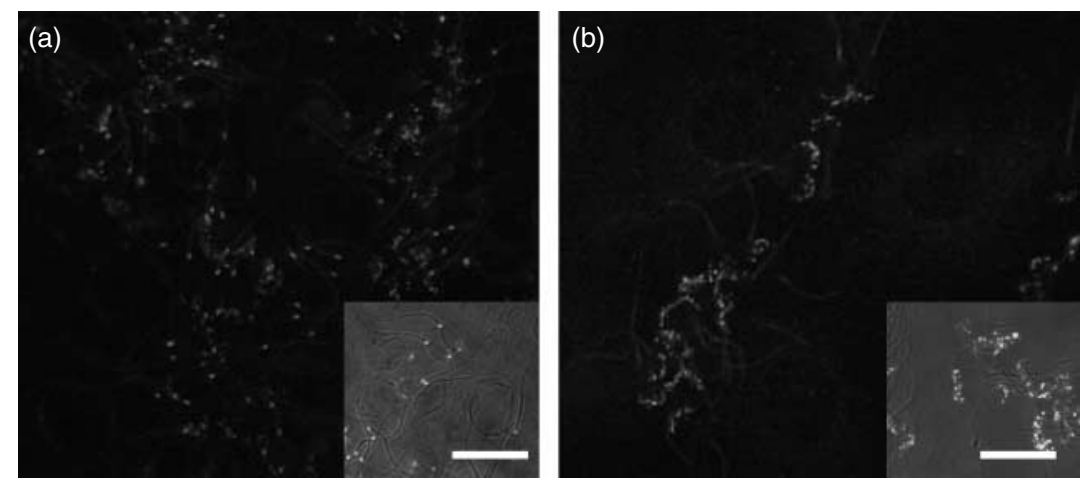

Figure 2 Immunolocalization of CB1 (a) and CB2 (b) in bovine spermatozoa bound to oviductal monolayers. Bar, $10 \mu \mathrm{m}$. Insets, half light-half fluorescence micrographs of CB localization. Bar, $20 \mu \mathrm{m}$. 

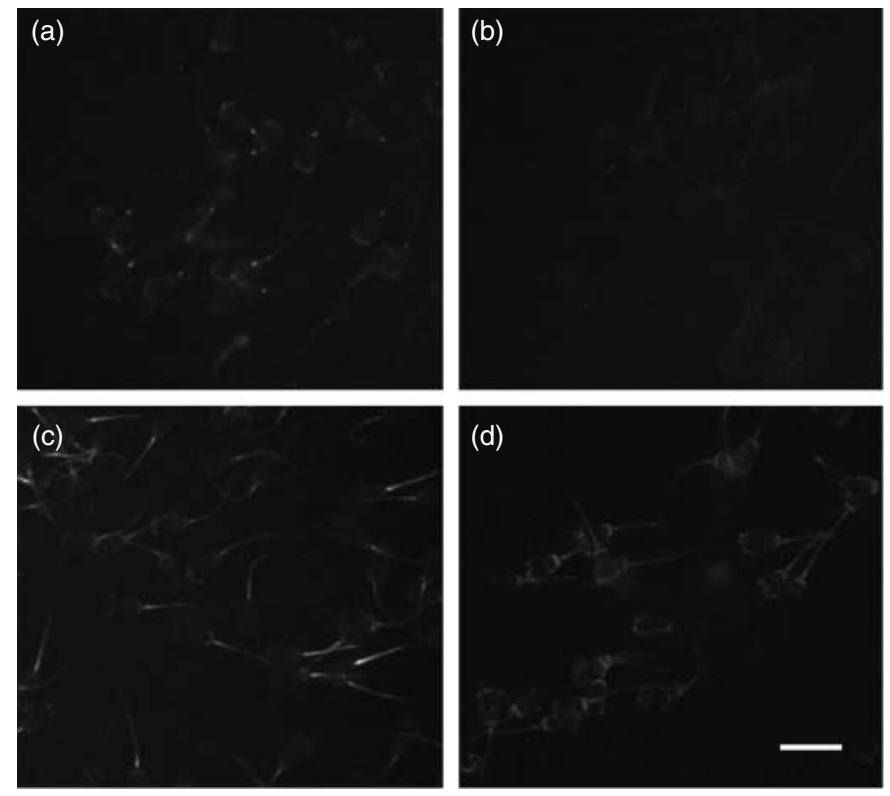

(e)

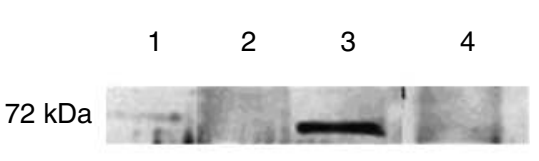

(f)

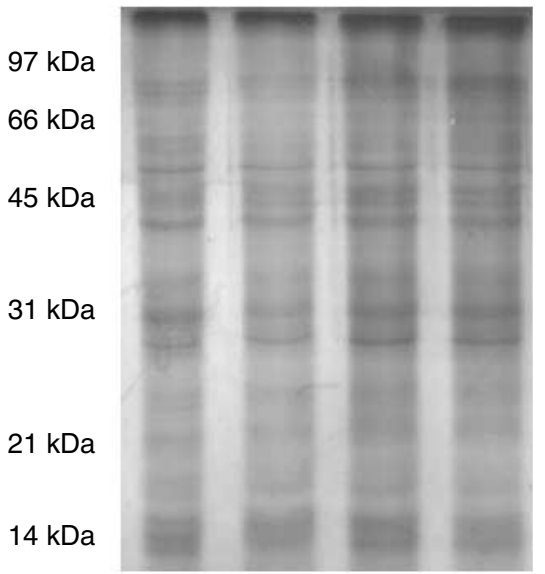

Figure 3 Immunolocalization of CB1 (a, b) and CB2 (c, d) in spermatozoa released by penicillamine (a, c) and heparin (b, d). Bar, $10 \mu \mathrm{m}$. Western blot of CB1 (e) in spermatozoa released by heparin (lanes 1 and 2) and penicillamine (lanes 3 and 4). Controls with the corresponding specific blocking peptides (lanes 2 and 4).

\section{Effect of AEA on sperm kinetics}

To determine the AEA effects on sperm motility, spermatozoa were exposed to 2, 5, and $10 \mu \mathrm{M}$ AEA $(n=4)$. AEA at 5 (Fig. 5) and $10 \mu \mathrm{M}$ (Fig. 6) induced a rapid and persistent decrease in kinetic parameters. However, the reduction in sperm kinetics was significant only for curvilinear velocity (VCL; Fig. 6a) and straight-line velocity (VSL; Fig. 6b) at $10 \mu \mathrm{M}$. Although at $5 \mu \mathrm{M}$ the depression of sperm kinetic parameters was not significant (Fig. 5), data indicate that the effects of AEA were reversible as all values were recovered compared with controls at $40 \mathrm{~min}$.

\section{AEA effect on sperm-oviduct interaction}

Recently, Gervasi et al. (2009) showed that nanomolar concentrations of AEA inhibited sperm-oviduct binding and induced sperm release in vitro. In the present study, AEA was tested at $2 \mathrm{nM}$ and $5 \mu \mathrm{M}(n=4)$. Quantitative analysis showed that after $30 \mathrm{~min}$ of treatment, AEA $2 \mathrm{nM}$ had no effects on sperm-oviduct binding (Fig. 7a, control $99 \pm 23$ versus AEA $88 \pm 17$ ), whereas AEA $5 \mu \mathrm{M}$ slightly decreased the number of spermatozoa bound to explants compared with controls (Fig. 7a, control $99 \pm 23$ versus AEA $81 \pm 16$ ). Moreover, AEA both at $2 \mathrm{nM}$ and $5 \mu \mathrm{M}$ was unable to induce a release of spermatozoa adhering to explants (Fig. 7b, control 194 \pm 43 versus AEA 2 nM $203 \pm 36$, AEA $5 \mu \mathrm{M} 198 \pm 32$ ).

\section{AEA effect on sperm-ZP binding}

One of the effect of AEA on the sperm physiology is to depress sperm capacitation. This experiment $(n=4)$ has been designed to understand whether a) AEA depresses sperm-ZP binding, and b) heparin-capacitated spermatozoa, which lack a CB1 immunoreactivity, are still responsive to AEA. Results demonstrated that $Z P$ binding was significantly depressed by AEA (control, Fig. 8b; AEA, Fig. 8c) and increased by heparin (Fig. 8). Interestingly, AEA was unable to depress ZP binding if spermatozoa were capacitated by pretreatment with heparin (Fig. 8a).

\section{RT-PCR analysis of NAPEPLD mRNA}

To investigate whether the bovine oviduct was able to synthesize endocannabinoids, total RNA was isolated from epithelial cells recovered from ampulla and isthmus and subjected to RT-PCR analysis of NAPEPLD. Data showed that both regions express mRNAs for NAPEPLD with similar intensity (Fig. 9).

\section{Discussion}

In mammals, among millions of spermatozoa ejaculated, only a few are able to enter the oviduct and transiently adhere to epithelial cells lining the isthmus. Adhesion to the oviduct prolongs the sperm fertile life, suggesting the presence of active controls for sperm selection and storage inside the female reproductive tract to 

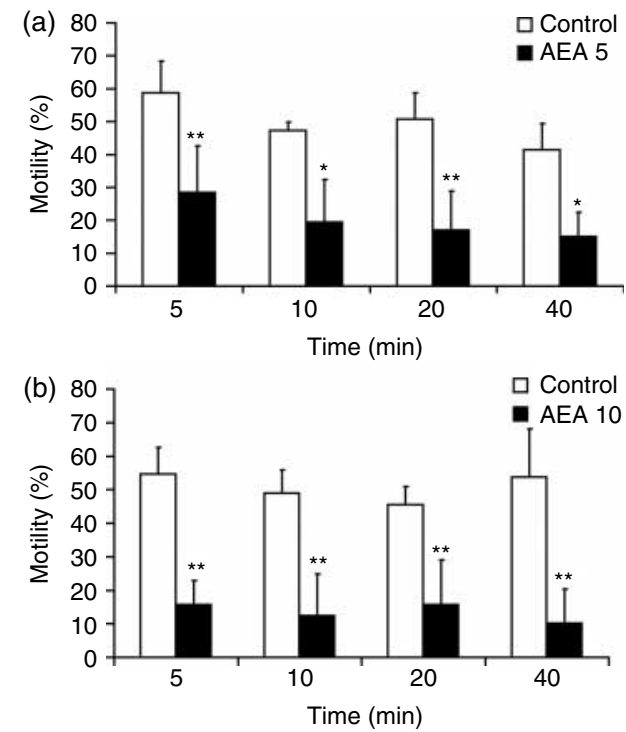

Figure 4 Progressive motility of spermatozoa treated with AEA 5 (a) and $10 \mu \mathrm{M}$ (b). Significance versus control: ${ }^{*} P<0.05$; ${ }^{*} P<0.01$.

ensure a successful fertilization and embryo development. The presence of the ECS and the discovery of an AEA gradient within the mammalian oviduct (Wang et al. 2006) suggest the intriguing possibility that endocannabinoids are involved in the complex mechanisms that regulate sperm storage, capacitation, and selection within the oviduct.

In the present paper, we studied the presence of endocannabinoid receptors on bovine spermatozoa, the effects of AEA on sperm physiology, and the ability of oviductal epithelial cells to synthesize endocannabinoids. Main results demonstrated that 1) $\mathrm{CB} 1$ and $\mathrm{CB} 2$ are present on bovine spermatozoa; 2) AEA does not influence sperm viability, whereas it induces a rapid decrease in sperm motility and kinetic parameters; 3) AEA does not affect sperm interaction with oviductal cells; 4) spermatozoa released from the oviduct through heparin, a powerful capacitating agent, showed a decreased detection in CB1; 5) AEA reduces sperm-ZP binding, but 6) fails to do so if spermatozoa were capacitated with heparin; 7) oviductal epithelial cells express NAPEPLD, the main enzyme involved in AEA synthesis. Taken together, these data suggest that endocannabinoids in the oviductal microenvironment could modulate the motility and capacitation of spermatozoa during their journey inside the female reproductive tract.

Several evidences suggest that ECS is active inside the reproductive tract of mammals (Taylor et al. 2007), and AEA has also been identified in human reproductive fluids (Schuel et al. 2002a, 2002b). An ECS has been demonstrated in human (Rossato et al. 2005, Francavilla et al. 2009), boar (Maccarrone et al. 2005), mouse (Ricci et al. 2007, Sun et al. 2009), and bovine (Gervasi et al. 2009). In mice, ECS modulates sperm motility during epididymal maturation, and high levels of endocannabinoids have been detected in mouse spermatozoa isolated from the caput of the epididymis, where they are functionally immotile, while low levels have been found in those isolated from the cauda where they acquire motility (Ricci et al. 2007, Cobellis et al. 2010). Inside the oviduct, the concentration of AEA is higher in the isthmus than in the ampulla. In the oviduct, a critical balance between AEA synthesis and its degradation creates locally an appropriate 'anandamide tone' that has been correlated with normal embryo development, oviductal transport, implantation, and pregnancy (Wang et al. 2006). However, until now, it is not known whether the presence of an oviductal AEA gradient plays a role in sperm transport and selection.

In the present paper, the presence of $\mathrm{CB} 1$ and $\mathrm{CB} 2$ in bovine spermatozoa has been demonstrated by both immunocytochemistry and western blot analysis, confirming a previous report by Gervasi et al. (2009). The different localizations of receptors detected herein could be due to the use of different antibodies in the immunolocalization procedure.
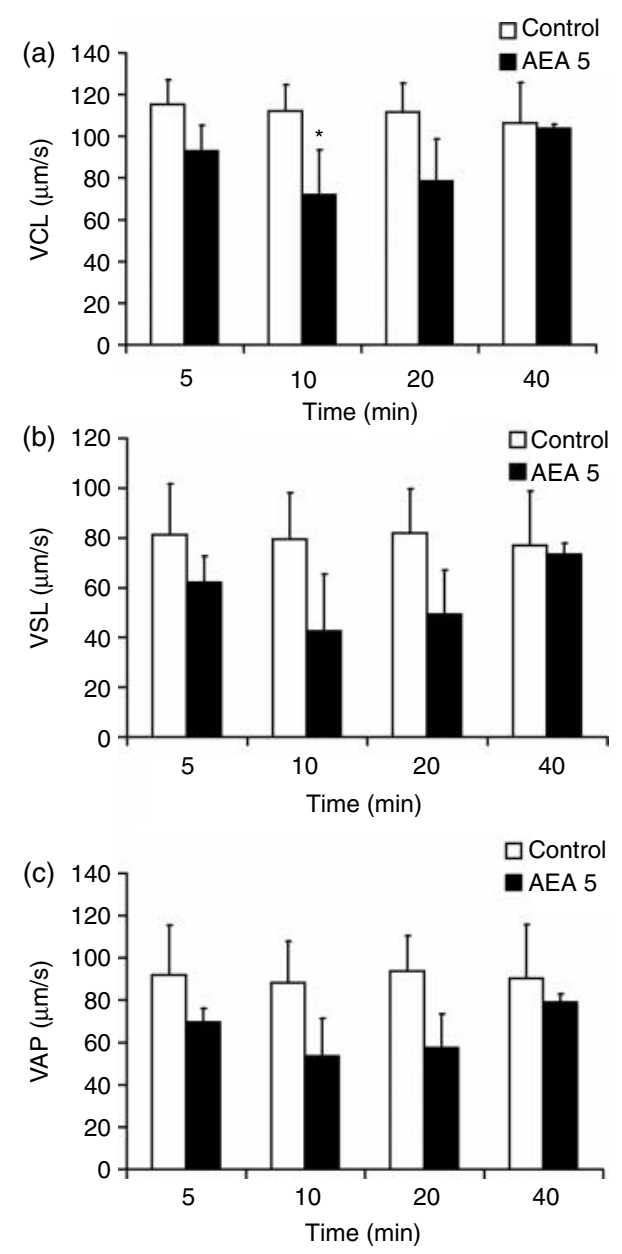

Figure 5 Kinetic parameters of spermatozoa treated with AEA $5 \mu \mathrm{M}$. Significance versus control: ${ }^{*} P<0.05$. 

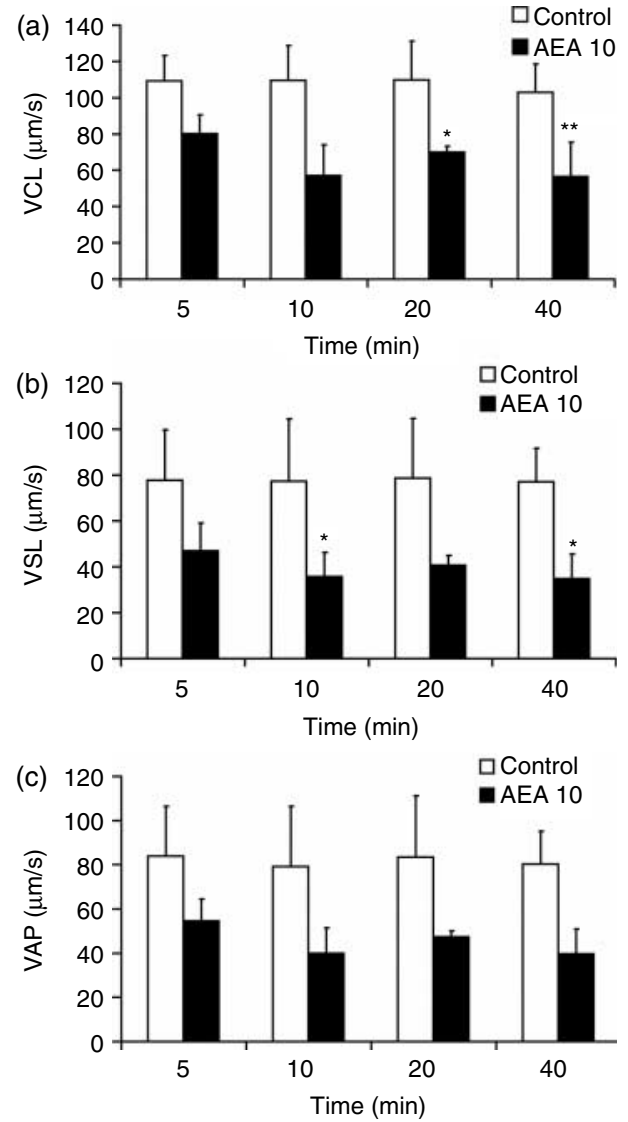

Figure 6 Kinetic parameters of spermatozoa treated with AEA $10 \mu \mathrm{M}$. Significance versus control: ${ }^{*} P<0.05$; ${ }^{* *} P<0.01$.

During the last years, experimental data have shown that endocannabinoids negatively influence sperm motility in several mammalian species (Schuel et al. 2002a, 2002 b, Rossato et al. 2005, Cobellis et al. 2006, Aquila et al. 2009, Francavilla et al. 2009). In human spermatozoa, the effect of AEA on the depression of motility has been demonstrated at both nanomolar (Aquila et al. 2009) and micromolar concentrations (Rossato et al. 2005), even though in the latter case the drop of motility was associated with a loss of sperm viability (Rossato et al. 2005, Rossato 2008). In bovine spermatozoa, observational analysis demonstrated that AEA at nanomolar concentrations does not affect motility (Gervasi et al. 2009). Herein, micromolar concentrations of AEA did not affect sperm viability but induced a rapid and persistent decrease in percent progressive motility and kinetic parameters. Moreover, although at $5 \mu \mathrm{M}$ the decrease in sperm VCL, VSL, and average path velocity (VAP) was not significant, a recovery of these kinetic parameters was observed after 40 min of treatment. This is likely to be due to AEA degradation at this time, and indicates that the effect of AEA on sperm kinetics may be reversed.

Herein, the concentrations of AEA that affect bovine sperm motility and kinetics in vitro are higher than those reported in reproductive fluids. Nanomolar concentrations of AEA have been reported in human seminal plasma, mid-cycle oviductal fluid (Schuel et al. 2002a, 2002b), as well as in plasma of pregnant women where an AEA level $<2 \mathrm{nM}$ has been shown to be required at the beginning of implantation to assist in uterine receptivity (El-Talatini et al. 2009). However, we do not know the levels of AEA inside the bovine oviduct and, moreover, in other species, the levels reported for plasma and whole oviduct fluids are average concentrations. Spermatozoa adhering to the oviductal cells are likely to be exposed to microenvironments containing concentrations of oviductal secretions higher than those reported in whole bovine ampullary and isthmic fluids (Parrish et al. 1989, Lapointe \& Bilodeau 2003, Bergqvist \& Rodríguez-Martínez 2006). Moreover, gametes are able to directly influence their own microenvironment. In fact, in the porcine species, spermatozoa and oocytes selectively modulate the oviductal secretory proteome (Georgiou et al. 2005). Here, we have shown that bovine epithelial cells express mRNAs for NAPEPLD, the main enzyme involved in AEA synthesis. Spermatozoa adhering to the oviductal cells could be exposed directly to the site of AEA production, and the local concentration of AEA might be higher than that found in the whole oviductal fluid. In mouse oviduct, a longitudinal gradient of AEA is created by a high concentration of NAPEPLD in the isthmus and a high concentration of FAAH, the main enzyme for AEA degradation inside the ampulla (Wang et al. 2006). In this respect, we hypothesize that a transversal AEA gradient is present between the site of AEA production, i.e. the epithelial cell where spermatozoa are attached, and the central region of the oviduct lumen. The presence of a higher AEA concentration in the isthmus (Wang et al. 2006), i.e. in the spermreservoir, raises the hypothesis that endocannabinoids have a role during the sperm ascension along the oviduct. In this respect, AEA has been reported to inhibit in vitro sperm-oviduct binding, and promotes sperm release (Gervasi et al. 2009). However, in the

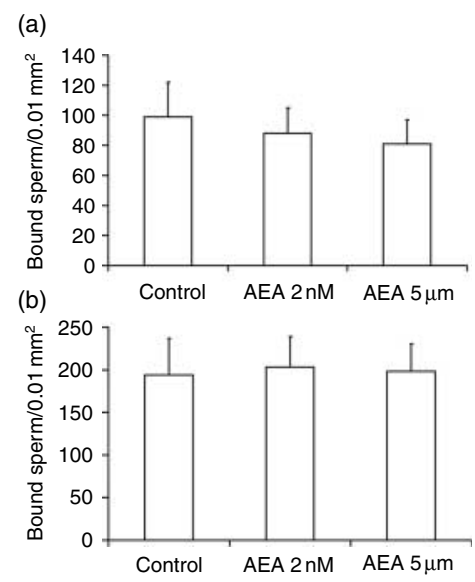

Figure 7 Effects of AEA on sperm-oviduct binding (a) and release (b). 

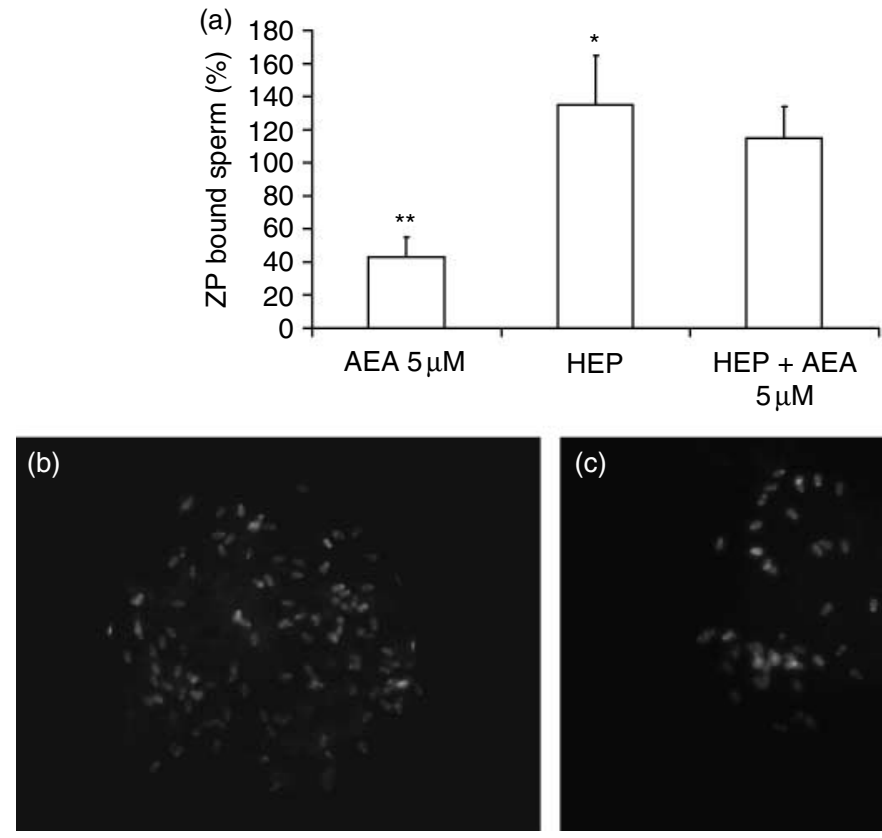

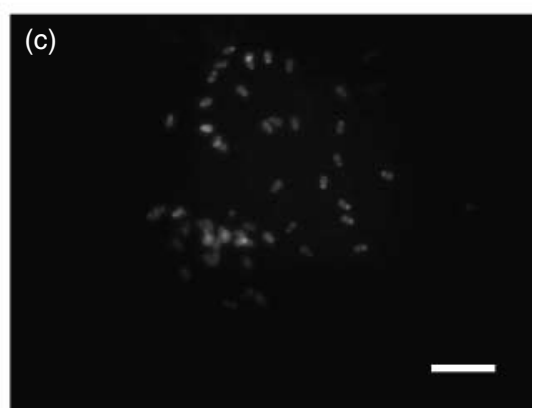

Figure 8 Effects of $A E A$, heparin (HEP), and heparin plus AEA (HEP+AEA) on sperm-ZP binding (a). Data are shown as percent of sperm-ZP binding respect to control that is assumed as $100 \%$. Sperm-ZP binding is depressed by AEA and enhanced by heparin. AEA does not depress sperm-ZP binding when spermatozoa are capacitated by heparin. (b) In vitro-matured oocyte inseminated with Hoechst-labeled control spermatozoa. (c) In vitro-matured oocyte inseminated with Hoechst-labeled spermatozoa pretreated with AEA. Bar, $20 \mu \mathrm{m}$. Significance versus control: ${ }^{*} P<0.05 ;{ }^{* *} P<0.01$. present study, we observed that AEA has no effects on sperm-oviduct binding and sperm release, even at a concentration of $5 \mu \mathrm{M}$. These data are in agreement with several evidences showing that release of spermatozoa bound to the oviductal reservoir is promoted by capacitation (Lefebvre \& Suarez 1996, Gualtieri et al. 2005, Talevi et al. 2007, Talevi \& Gualtieri 2010), whereas AEA has been shown to depress this process, at least in human and boar (Rossato et al. 2005, Maccarrone et al. 2005). Herein, sperm-ZP binding experiments demonstrated that AEA depresses sperm capacitation also in the bovine species.

Heparin and penicillamine are powerful inducers of the release of bovine spermatozoa adhering to in vitrocultured oviductal epithelium, and have been suggested to represent physiological signals for release of spermatozoa sequestered in the oviduct (Talevi \& Gualtieri 2001, Talevi et al. 2007). Both release inducers act on spermatozoa and trigger capacitation-related changes (Gualtieri et al. 2005, Talevi et al. 2007). Although both inducers trigger capacitation, we showed that only spermatozoa capacitated by penicillamine are able to revert this process (Gualtieri et al. 2009). Interestingly, CB1 was not detectable in heparin-released spermatozoa by both immunocytochemistry and western blot analysis, whereas, in spermatozoa released by

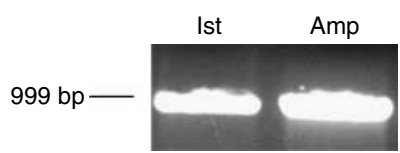

Figure 9 RT-PCR analysis of NAPEPLD mRNA expression in bovine oviductal epithelial cells. Ist, isthmus; Amp, ampulla. penicillamine, CB1 had the same immunolocalization observed in the initial sperm population. The lack of CB1 immunoreactivity in heparin-released spermatozoa could be due to a remodeling of the sperm surface induced by capacitation. Interestingly, sperm-ZP binding experiments showed that heparin-capacitated spermatozoa failed to respond to AEA, thus indicating that the observed lack of immunoreactivity was associated with a loss of functionality of the CB1 receptor.

In conclusion, data here reported support the hypothesis that ECS has an active role during the sperm transport within the female reproductive tract. Secretion of AEA from epithelial cells might contribute to the oviduct sperm-reservoir function, prolonging the sperm fertile life through the depression of motility and capacitation. Capacitation signals, such as heparin, that promote sperm release might remodel the sperm surface and cause a loss of the sperm sensitivity to AEA.

\section{Materials and Methods}

\section{Chemicals}

BSA (fraction V), penicillamine, heparin (sodium salt, purified from porcine intestinal mucosa; H3393), protease inhibitor cocktail (P2714), AEA, estradiol $\left(\mathrm{E}_{2}\right), \mathrm{FSH}, \mathrm{LH}$, and Medium 199 (M4530) were purchased from Sigma Chemical Company; FCS, gentamycin, amphotericin B, HEPES, and sodium bicarbonate were purchased from Gibco. Anti-CB1 and anti-CB2 rabbit antibodies and the corresponding specific blocking peptides were purchased from Cayman Chemical (Inalco, Milan, Italy). Reagents and buffers for SDS-PAGE, including the molecular weight Precision Plus Protein Standards, were purchased from Bio-Rad. ImmunoPure Standard ABC Staining kit and BCA Protein Assay kit were purchased from Pierce (Milan, Italy). 
Nitrocellulose (0.45- $\mu \mathrm{m}$ pore size; PROTRAN) was purchased from Whatman (Dassel, Germany). Reagents and water for preparation of salines and culture media were all cell culture tested.

\section{Preparation of oviductal epithelial cells}

Oviducts were collected at the time of slaughter and transported to the laboratory in Dulbecco's PBS (DPBS) supplemented with $50 \mu \mathrm{g} / \mathrm{ml}$ gentamycin at $4{ }^{\circ} \mathrm{C}$. Laminae of epithelial cells were recovered from oviducts of single animals by squeezing and cultured at $39{ }^{\circ} \mathrm{C}, 5 \% \mathrm{CO}_{2}$ in air, 95\% humidity, in $\mathrm{M} 199$ supplemented with $50 \mu \mathrm{g} / \mathrm{ml}$ gentamycin, $1 \mu \mathrm{g} / \mathrm{ml}$ amphotericin B, and $10 \%$ FCS. Bovine oviductal epithelial cells were either used as swimming-everted vesicles, referred to as explants, within $24 \mathrm{~h}$ of culture, or as confluent monolayers. To this end, explants were initially cultured in 10-cm Petri dishes (Falcon; Becton Dickinson, Milan, Italy) for 24-48 h, and then transferred into four-well tissue culture plates (Nunclon, Roskilde, Denmark) with $12 \mathrm{~mm}$, gelatin-coated, German glass round cover slips on the well bottom or on gelatine-coated 10-cm Petri dishes. Fresh media changes were performed every $48 \mathrm{~h}$. Cell confluence was attained in about 7-10 days, and monolayers were used within $24 \mathrm{~h}$ after attainment of cell confluence. Within each experiment, oviductal monolayers from a single individual were washed three times in TALP (Parrish et al. 1989), modified as described in Paula-Lopes et al. (1998), and left in this medium until sperm addition (0.5-1 h).

\section{Sperm preparation}

Frozen bovine semen $\left(0.5-\mathrm{ml}\right.$ straws; $\sim 40 \times 10^{6}$ spermatozoa per straw; motility after thawing R70\%), obtained from Semen Italy (San Giuliano Saliceta, Modena, Italy), was used in all experiments. Straws were thawed in a water bath at $38{ }^{\circ} \mathrm{C}$ for $30 \mathrm{~s}$, and $0.5 \mathrm{ml}$ of semen was either labeled with $10 \mu \mathrm{g} / \mathrm{ml}$ Hoechst 33342 for $5 \mathrm{~min}$ at $39{ }^{\circ} \mathrm{C}, 5 \% \mathrm{CO}_{2}$ in air, or directly washed in $10 \mathrm{ml}$ and then in $5 \mathrm{ml}$ TALP with or without BSA (BSA-free TALP), by centrifugation at $170 \mathrm{~g}$ for 10 and $5 \mathrm{~min}$ respectively. After resuspension in fresh medium, recovered spermatozoa were assessed for concentration and percent motility using a hemocytometer placed on a microscope stage heated to $39^{\circ} \mathrm{C}$.

\section{Sperm-oviduct adhesion and release}

Sperm suspensions recovered after centrifugation in TALP were added to bovine oviductal monolayers cultured on gelatinecoated, $12 \mathrm{~mm}$, round cover slips in NUNC four-well plates in $750-\mu \mathrm{l}$ TALP at a concentration of $1-1.5 \times 10^{6} / \mathrm{cm}^{2}$, and incubated at $39{ }^{\circ} \mathrm{C}, 5 \% \mathrm{CO}_{2}$ in air, $95 \%$ humidity, for $30 \mathrm{~min}$. At the end of coincubation, monolayers were extensively washed with TALP to remove unbound spermatozoa. A series of monolayers with adhering spermatozoa were air-dried and processed for immunocytochemical analysis, whereas parallel monolayers were treated for sperm release by incubation with freshly prepared $0.1 \mathrm{mM}$ penicillamine or with $100 \mu \mathrm{g} / \mathrm{ml}$ heparin for $30 \mathrm{~min}$. At the end of treatment, released spermatozoa were collected and fixed for immunocytochemical and western blot analysis.

\section{Effect of AEA on sperm-oviduct interaction}

To detect the effect of AEA on sperm-oviduct binding, sperm suspensions were added to explants in four-well plates at a concentration of $1-2 \times 10^{6}$ motile spermatozoa/well in $750 \mu \mathrm{l}$ TALP added or less with AEA $2 \mathrm{nM}, 5 \mu \mathrm{M}$, and incubated at $39{ }^{\circ} \mathrm{C}, 5 \% \mathrm{CO}_{2}$ in air, $95 \%$ humidity, for $30 \mathrm{~min}$. At the end of coincubation, unbound spermatozoa were removed by extensive washings with TALP, and cocultures were fixed to quantify the number of adhering spermatozoa as previously described (Gualtieri et al. 2009). To detect the effect of AEA on spermoviduct release, explants were inseminated in TALP as above, and after unbound sperm removal, cocultures were treated with AEA $2 \mathrm{nM}, 5 \mu \mathrm{M}$, or TALP alone, and analyzed.

\section{Localization of $C B 1$ and $C B 2$ receptors in bovine spermatozoa by immunocytochemistry}

Initial and released sperm suspensions were diluted to $5 \times 10^{6} / \mathrm{ml}$ in DPBS, smeared on glass slides, allowed to air dry, fixed in cold methanol $\left(-20^{\circ} \mathrm{C}\right)$ for $5 \mathrm{~min}$, washed three times for $10 \mathrm{~min}$ in PBS, and then processed for immunocytochemistry. To this aim, slides were treated $5 \mathrm{~min}$ at room temperature in $1 \% \mathrm{BSA}, 0.1 \%$ Tween 20 , in PBS, incubated $1 \mathrm{~h}$ at $37{ }^{\circ} \mathrm{C}$ in anti-CB1 or anti-CB2 rabbit antibodies (1:50; Cayman Chemical) in PBS, washed three times for $10 \mathrm{~min}$ in PBS, incubated in the darkness for $2 \mathrm{~h}$ at $37^{\circ} \mathrm{C}$ in FITCconjugated goat anti-rabbit IgG (1:600), washed again three times for $10 \mathrm{~min}$ in PBS, mounted, and observed at a Nikon TE 2000 fluorescence microscope. Images were acquired using a Nikon DS-cooled camera head DS-5Mc connected to a Nikon DS camera control unit DS-L1 using the same exposure conditions. Specificity controls were performed through omission of the primary antibody or through preincubation of anti-CB1 or anti-CB2 rabbit antibodies with the corresponding specific blocking peptide (Cayman Chemical; antibody/peptide 1/5) and subsequent incubation of slides in this mixture.

\section{SDS-PAGE and western blot analysis of CB1 and CB2 receptors}

Spermatozoa were centrifuged twice at $180 \mathrm{~g}$ for $10 \mathrm{~min}$ in BSA-free sperm-TALP $\left(170 \times 10^{6} \mathrm{ml}\right.$ for each sample), resuspended in $50 \mathrm{mM}$ Tris ( $\mathrm{pH}$ 7.4) and protease inhibitor cocktail, and centrifuged at $800 \mathrm{~g}$ for $10 \mathrm{~min}$. The pellet was resuspended $1: 1 \mathrm{v} / \mathrm{v}$ in lysis medium containing $50 \mathrm{mM}$ Tris (pH 7.4), $2 \mathrm{mM}$ EDTA $0.4 \%$ Triton X-100, and protease inhibitor cocktail left on ice for $30 \mathrm{~min}$ and centrifuged at $13000 \mathrm{~g}$ for $8 \mathrm{~min}$ at $4{ }^{\circ} \mathrm{C}$. Protein concentration in the supernatants was determined with BCA Protein Assay kit (Pierce) and stored at $-20^{\circ} \mathrm{C}$. Aliquots of supernatant containing $15 \mu \mathrm{g}$ of protein were subjected to SDS-PAGE ( $9 \%$ gels) transferred to $0.45-\mu \mathrm{m}$ pore nitrocellulose membranes, incubated overnight at $4{ }^{\circ} \mathrm{C}$ with anti-CB1 or anti-CB2 rabbit antibodies (1:250; Cayman Chemical) in Tris-buffered saline with $5 \%$ nonfat dry milk, and then for $1 \mathrm{~h}$ at room temperature in HRP-conjugated goat anti-rabbit IgG (1:2000). Specificity controls were performed through preincubation of anti-CB1 or 
anti-CB2 rabbit antibodies with the corresponding specific blocking peptide (Cayman Chemical; antibody/peptide 1/5). The nitrocellulose membranes were developed using an ECL detection system (Pierce). In experiments on released spermatozoa, two parallel gels were prepared; one was electroblotted and the other was silver-stained to ascertain that the same amount of proteins was applied.

\section{Evaluation of sperm viability, progressive motility, and kinetics}

Sperm viability was evaluated at a bright field light microscope with the eosin/nigrosin test (Tartaglione \& Ritta 2004). Progressive motility and kinetics, i.e. VCL, VSL, VAP, were evaluated by Sperm Class analyzer (SCA Microptic S.L., Barcelona, Spain) with the following software setting: frame rates: 25 frames/s; number of frames: 10 frames/object; velocity limit for slow spermatozoa: $25 \mu \mathrm{m} / \mathrm{s}$; velocity limit for medium spermatozoa: $35 \mu \mathrm{m} / \mathrm{s}$; velocity limit for rapid spermatozoa: $50 \mu \mathrm{m} / \mathrm{s}$; minimal linearity $50 \%$; straightness for progressive fast spermatozoa $70 \%$. In all AEA experiments, spermatozoa were washed with BSA-free TALP to avoid the formation of BSA-endocannabinoid complexes, and controls were added with the same concentration of vehicle present in AEA-treated samples. Sperm suspensions in BSA-free TALP were divided into aliquots and treated with AEA 2, 5, and $10 \mu \mathrm{M}$, or TALP alone. Samples were loaded into a Makler chamber and analyzed on a heated stage at $37{ }^{\circ} \mathrm{C}$ at 5, 10, 20, and $40 \mathrm{~min}$ after treatment, at a Nikon TE 2000 inverted microscope connected to a Basler Vision Technology A312 fc camera with a negative phase contrast $10 \times$ objective. To avoid sperm attachment to the bottom of the chamber, samples were diluted 1:1 v/v with TALP containing a double concentration of BSA at the time of analysis. For each time point, at least 200 cells and four fields were acquired and analyzed.

\section{Oocyte collection and in vitro maturation}

Ovaries were collected at the time of slaughter and transported to the laboratory in $0.9 \% \mathrm{NaCl}$ solution supplemented with $50 \mu \mathrm{g} / \mathrm{ml}$ gentamycin at $37^{\circ} \mathrm{C}$. Cumulus-oocyte complexes (COCs) were then collected by aspiration of individual follicles with an 18-gauge needle in $\mathrm{M} 199,50 \mu \mathrm{g} / \mathrm{ml}$ gentamycin, $1 \mu \mathrm{g} / \mathrm{ml}$ amphotericin B, and $10 \%$ FCS. COCs were matured in the same medium supplemented with $2 \mu \mathrm{g} / \mathrm{ml} \mathrm{E}_{2}, 0.1 \mathrm{IU} / \mathrm{ml}$ $\mathrm{FSH}$, and $10 \mathrm{IU} / \mathrm{ml} \mathrm{LH}$ (Sigma) for $24 \mathrm{~h}$ at $39{ }^{\circ} \mathrm{C}, 5 \% \mathrm{CO}_{2}$ in air, 95\% humidity.

\section{Sperm-ZP binding assays}

Hoechst-labeled sperm suspensions recovered after centrifugation in BSA-free TALP were pretreated as follows: 1) TALP $20 \mathrm{~min}$ plus AEA $5 \mu \mathrm{M} 10 \mathrm{~min}$; 2) $100 \mu \mathrm{g} / \mathrm{ml}$ heparin $20 \mathrm{~min}$ plus AEA $5 \mu \mathrm{M} 10 \mathrm{~min}$; 3) $100 \mu \mathrm{g} / \mathrm{ml}$ heparin $20 \mathrm{~min}$ plus vehicle $10 \mathrm{~min}$; 4) TALP $20 \mathrm{~min}$ plus vehicle $10 \mathrm{~min}$ as control. In vitro-matured COCs were denuded by vortexing in M199 supplemented with $0.5 \mathrm{mg} / \mathrm{ml}$ polyvinyl alcohol and $50 \mu \mathrm{g} / \mathrm{ml}$ gentamycin. The denuded oocytes were placed in groups of 20-25 in four-well plates in $500 \mu$ l BSA-free TALP.
Oocytes were inseminated for $30 \mathrm{~min}$ at a concentration of $1 \times 10^{6}$ motile spermatozoa/well with the sperm suspensions described above and in the presence of the same concentration of reagents used in the sperm pretreatment. At the end of the incubation, oocytes were rinsed five times in the same medium using flexipet adjustable handle set (Cook Italia SRL, Milan, Italy) with $140-\mu \mathrm{m}$ denuding pipette to dislodge loosely bound spermatozoa, fixed for $1 \mathrm{~h}$ at room temperature in $2.5 \%$ glutaraldehyde in PBS, washed in PBS, and mounted on glass slides. Oocytes were compressed under the cover slips to visualize all bound spermatozoa in a single focus plane, and images were acquired using a Nikon Eclipse TE 2000 inverted microscope under fluorescence, by means of Nikon DS-cooled camera head DS-5Mc and NIS AR software (Nikon, Florence, Italy).

\section{RT-PCR analysis of NAPEPLD $m R N A$}

Total RNA was isolated from epithelial cells recovered from the isthmus and the ampulla of bovine oviducts using Nucleo Spin RNA II (GE Healthcare, Amersham, Bucks, UK) according to the manufacturer's recommendations.

First-strand cDNA was synthesized from $5-\mu$ g total RNA, using random primers and reverse transcriptase provided by Super Script First-Strand Synthesis System for RT-PCR (Invitrogen). After first-strand synthesis, PCR was performed with the following oligonucleotide primer couples: 5'-GGTCTTCACCAAAGAACATGG-3' (forward), 3'-TCTTTACAGCCTCTTCTGGG-5' (reverse) for a product length of 999 nucleotides. The primers were designed in Primer-BLAST on the NAPEPLD bovine mRNA sequences available in NCBI (Bos taurus NAPEPLD, mRNA, complete cds gi|61555755|gb|BT021908.1| [61555755]). Amplifications were performed using DreamTaq DNA polymerase (Fermentas, Vilnius, Lithuania). PCR was performed as follows: $95^{\circ} \mathrm{C}$ for $2 \mathrm{~min}$ (initial denaturation) and 30 cycles at $94{ }^{\circ} \mathrm{C}$ for $45 \mathrm{~s}, 50{ }^{\circ} \mathrm{C}$ for $30 \mathrm{~s}$, and $68{ }^{\circ} \mathrm{C}$ for $1.5 \mathrm{~min}$. PCR products were separated on a $1.2 \%(\mathrm{w} / \mathrm{v})$ agarose gel, stained with ethidium bromide, and recorded under u.v. light with a digital Camera. cDNAs were cloned into a pCR II vector (Invitrogen Life Technologies) and sequenced by PRIMM (Naples, Italy). All sequence information was processed using BlastN program.

\section{Statistical analysis}

The data are presented as mean \pm s.D. Overall, analysis was performed by the estimate model of ANOVA (SAS/STAT 1988) followed by the Tukey's honest significant difference test for pairwise comparisons when overall significance was detected. Results expressed as percentages were modified by arcsine transformation to normalize the data.

\section{Declaration of interest}

The authors declare that there is no conflict of interest that could be perceived as prejudicing the impartiality of the research reported. 


\section{Funding}

Supported by P.R.I.N. grant 2006.

\section{References}

Aquila S, Guido C, Laezza C, Santoro A, Pezzi V, Panza S, Andò S \& Bifulco M 2009 A new role of anandamide in human sperm: focus on metabolism. Journal of Cellular Physiology 221 147-153.

Bergqvist AS \& Rodríguez-Martínez H 2006 Sulphated glycosaminoglycans (S-GAGs) and syndecans in the bovine oviduct. Animal Reproduction Science 93 46-60.

Cacciola G, Chioccarelli T, Ricci G, Meccariello R, Fasano S, Pierantoni R \& Cobellis G 2008 The endocannabinoid system in vertebrate male reproduction: a comparative overview. Molecular and Cellular Endocrinology 286 S24-S30.

Cobellis G, Cacciola G, Scarpa D, Meccariello R, Chianese R, Franzoni MF, Mackie K, Pierantoni R \& Fasano S 2006 Endocannabinoid system in frog and rodent testis: type- 1 cannabinoid receptor and fatty acid amide hydrolase activity in male germ cells. Biology of Reproduction 75 82-89.

Cobellis G, Ricci G, Cacciola G, Orlando P, Petrosino S, Cascio MG, Bisogno T, De Petrocellis L, Chioccarelli T, Altucci L et al. 2010 A gradient of 2-arachidonoylglycerol regulates mouse epididymal sperm cell start-up. Biology of Reproduction 82 451-458.

Devane WA, Hanus L, Breuer A, Pertwee RG, Stevenson LA, Griffin G, Gibson D, Mandelbaum A, Etinger A \& Mechoulam R 1992 Isolation and structure of a brain constituent that binds to the cannabinoid receptor. Science 258 1946-1949.

Demott RP \& Suarez SS 1992 Hyperactivated sperm progress in the mouse oviduct. Biology of Reproduction 46 779-785.

El-Talatini MR, Taylor AH \& Konje JC 2009 Fluctuation in anandamide levels from ovulation to early pregnancy in in vitro fertilization-embryo transfer women, and its hormonal regulation. Human Reproduction $\mathbf{8}$ 1989-1998.

Felder CC \& Glass M 1998 Cannabinoid receptors and their endogenous agonists. Annual Reviews of Pharmacology and Toxicology 38 179-200.

Francavilla F, Battista N, Barbonetti A, Vassallo MRC, Rapino C, Antonangelo C, Pasquariello N, Catanzaro G, Barboni B \& Maccarrone M 2009 Characterization of the endocannabinoid system in human spermatozoa and involvement of transient receptor potential vanilloid 1 receptor in their fertilizing ability. Endocrinology $\mathbf{1 5 0}$ 4692-4700.

Georgiou AS, Sostaric E, Wong CH, Snijders AP, Wright PC, Moore HD \& Fazeli A 2005 Gametes alter the oviductal secretory proteome. Molecular and Cellular Proteomics 4 1785-1796.

Gervasi MG, Rapanelli M, Ribeiro ML, Farina M, Billi S, Franchi AM \& Perez Martinez S 2009 The endocannabinoid system in bull sperm and bovine oviductal epithelium: role of anandamide in sperm-oviduct interaction. Reproduction 137 403-414.

Gualtieri R, Boni R, Tosti E, Zagami M \& Talevi R 2005 Intracellular calcium and protein tyrosine phosphorylation during the release of bovine sperm adhering to the fallopian tube epithelium in vitro. Reproduction 129 51-60.

Gualtieri R, Mollo V, Duma G \& Talevi R 2009 Redox control of surface protein sulfhydryls in bovine spermatozoa reversibly modulates sperm adhesion to the oviductal epithelium and capacitation. Reproduction $13833-43$.

Habayeb OM, Bell SC \& Konje JC 2002 Endogenous cannabinoids: metabolism and their role in reproduction. Life Sciences 70 1963-1977.

Hunter RHF 1988 Transport of gametes, selection of spermatozoa and gamete lifespans in the female tracts. In The Fallopian Tubes, pp 53-80. Ed. RHF Hunter. New York: Springer-Verlag.

Hunter RH 2008 Sperm release from oviduct epithelial binding is controlled hormonally by peri-ovulatory graafian follicles. Molecular Reproduction and Development 75 167-174.

Hunter RH \& Rodriguez-Martinez H 2004 Capacitation of mammalian spermatozoa in vivo, with a specific focus on events in the Fallopian tubes. Molecular Reproduction and Development 67 243-250.

Lapointe J \& Bilodeau JF 2003 Antioxidant defenses are modulated in the cow oviduct during the estrous cycle. Biology of Reproduction $\mathbf{6 8}$ $1157-1164$
Lefebvre R \& Suarez SS 1996 Effect of capacitation on bull sperm binding to homologous oviductal epithelium. Biology of Reproduction $\mathbf{5 4}$ 575-582.

Lewis SE \& Maccarrone M 2009 Endocannabinoids, sperm biology and human fertility. Pharmacological Research 60 126-131.

Maccarrone M, Cecconi S, Rossi G, Battista N, Pauselli R \& Finazzi-Agrò A 2003 Anandamide activity and degradation are regulated by early postnatal aging and follicle-stimulating hormone in mouse Sertoli cells. Endocrinology 144 20-28.

Maccarrone M, Barboni B, Paradisi A, Bernabò N, Gasperi V, Pistilli MG, Fezza F, Lucidi P \& Mattioli M 2005 Characterization of the endocannabinoid system in boar spermatozoa and implications for sperm capacitation and acrosome reaction. Journal of Cell Science $\mathbf{1 1 8}$ 4393-4404.

McPartland JM, Glass M \& Pertwee RG 2007 Meta-analysis of cannabinoid ligand binding affinity and receptor distribution: interspecies differences. British Journal of Pharmacology 152 583-593.

Nakanishi T, Isotani A, Yamaguchi R, Ikawa M, Baba T, Suarez SS \& Okabe M 2004 Selective passage through the uterotubal junction of sperm from a mixed population produced by chimeras of calmegin-knockout and wild-type male mice. Biology of Reproduction 71 959-965.

Parrish JJ, Susko-Parrish JL, Handrow RR, Sims MM \& First NI 1989 Capacitation of bovine spermatozoa by oviduct fluid. Biology of Reproduction 40 1020-1025.

Paula-Lopes FF, de Moraes AA, Edwards JL, Justice JE \& Hansen PJ 1998 Regulation of preimplantation development of bovine embryos by interleukin-1 beta. Biology of Reproduction 59 1406-1412.

Ricci G, Cacciola G, Altucci L, Meccariello R, Pierantoni R, Fasano S \& Cobellis G 2007 Endocannabinoid control of sperm motility: the role of epididymus. General and Comparative Endocrinology 153 320-322.

Rossato M 2008 Endocannabinoids, sperm functions and energy metabolism. Molecular and Cellular Endocrinology 286 S31-S35.

Rossato M, Ion Popa F, Ferigo M, Clari G \& Foresta C 2005 Human sperm express cannabinoid receptor $\mathrm{Cb} 1$, the activation of which inhibits motility, acrosome reaction, and mitochondrial function. Journal of Clinical Endocrinology and Metabolism 90 984-991.

SAS Institute 1988 SAS/STAT User's Guide, Version 6.03. Cary, NC: Statistical Analysis System Institute.

Schuel H \& Burkman LJ 2005 A tale of two cells: endocannabinoidsignaling regulates functions of neurons and sperm. Biology of Reproduction 73 1078-1086.

Schuel H, Burkman LJ, Lippes J, Crickard K, Forester E, Piomelli D \& Giuffrida A 2002a N-Acylethanolamines in human reproductive fluids. Chemistry and Physics of Lipids 121 211-227.

Schuel H, Burkman LJ, Lippes J, Crickard K, Mahony MC, Giuffrida A, Picone RP \& Makriyannis A $2002 b$ Evidence that anandamide-signaling regulates human sperm functions required for fertilization. Molecular Reproduction and Development 63 376-387.

Smith TT \& Yanagimachi R 1990 The viability of hamster spermatozoa stored in the isthmus of the oviduct: the importance of spermepithelium contact for sperm survival. Biology of Reproduction 42 450-457.

Sun X, Wang H, Okabe M, Mackie K, Kingsley PJ, Marnett LJ, Cravatt BF \& Dey SK 2009 Genetic loss of Faah compromises male fertility in mice. Biology of Reproduction 80 235-242.

Talevi R \& Gualtieri R 2001 Sulfated glycoconjugates are powerful modulators of bovine sperm adhesion and release from the oviductal epithelium in vitro. Biology of Reproduction 64 491-498.

Talevi R \& Gualtieri R 2010 Molecules involved in sperm-oviduct adhesion and release. Theriogenology 73 796-801.

Talevi R, Zagami M, Castaldo M \& Gualtieri R 2007 Redox regulation of sperm surface thiols modulates adhesion to the fallopian tube epithelium. Biology of Reproduction 76 728-735.

Tartaglione CM \& Ritta MN 2004 Prognostic value of spermatological parameters as predictors of in vitro fertility of frozen-thawed bull semen. Theriogenology 62 1245-1252.

Taylor AH, Ang C, Bell SC \& Konje JC 2007 The role of the endocannabinoid system in gametogenesis, implantation and early pregnancy. Human Reproduction Update 13 501-513. 
Wang H, Guo Y, Wang D, Kingsley PJ, Marnett LJ, Das SK, DuBois RN \& Dey SK 2004 Aberrant cannabinoid signaling impairs oviductal transport of embryos. Nature Medicine 10 1074-1080.

Wang H, Xie H, Guo Y, Zhang H, Takahashi T, Kingsley PJ, Marnett LJ, Das SK, Cravatt BF \& Dey SK 2006 Fatty acid amide hydrolase deficiency limits early pregnancy events. Journal of Clinical Investigation $\mathbf{1 1 6}$ $2122-2131$.

Wilmut I \& Hunter RH 1984 Sperm transport into the oviducts of heifers mated early in oestrus. Reproduction, Nutrition, Development 24 461-468.
Yanagimachi R 1994 Mammalian fertilization. In The Physiology of Reproduction, vol 1, 2nd edn, pp 189-317. Eds E Knobil \& JD Neill. New York: Raven Press.

Received 16 February 2010

First decision 15 March 2010

Accepted 28 May 2010 